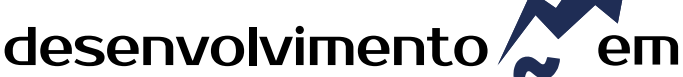 QUESTÂO
}

\section{ANÁLISE DA COMPETITIVIDADE DAS EXPORTAÇÕES DE MINÉRIOS DE FERRO NÃO AGLOMERADOS E AGLOMERADOS E SEUS CONCENTRADOS NO BRASIL: 2004 a 2018}

http://dx.doi.org/10.21527/2237-6453.2021.55.10537

Recebido em: 10/4/2020

Aceito em: 13/4/2021

Manoel Alexandre de Lucena ${ }^{1}$, Eliane Pinheiro de Sousa ${ }^{2}$

\begin{abstract}
RESUMO
O presente estudo propôs-se a avaliar o desempenho exportador do segmento de minérios de ferro não aglomerados e aglomerados e seus concentrados no Brasil e identificar as fontes de crescimento das exportações brasileiras desses produtos no período de 2004 a 2018. Para tal, utilizaram-se os índices de vantagem comparativa revelada, vantagem comparativa revelada simétrica, vantagem comparativa revelada de Vollrath e o modelo Constant-Market-Share, considerando, neste último, três subperíodos: 2004-2008, 2009-2013 e 2014-2018. Os resultados indicam que os Estados de Minas Gerais e Pará apresentaram vantagem comparativa em relação ao Brasil para minérios de ferro no segmento não aglomerados em todo o período analisado. Quanto aos minérios de ferro aglomerados, verifica-se a presença de vantagem comparativa do Estado do Espírito Santo em relação ao Brasil, porém não ocorre o mesmo para o Estado de Minas Gerais. Quanto às fontes de crescimento, constata-se que o efeito crescimento do comércio mundial afetou negativamente as exportações de minérios ferrosos no terceiro subperíodo em relação ao segundo. Por seu turno, o efeito destino das exportações foi o que mais contribuiu quando comparado o terceiro subperíodo com o segundo em ambos os segmentos, assim como o efeito competitividade, que, apesar de baixo, mostrou-se positivo nos dois subperíodos para as commodities analisadas.
\end{abstract}

Palavras-chave: Comércio internacional. Minérios de ferro. Vantagens comparativas reveladas. Constant-Market-Share.

\section{ANALYSIS OF COMPETITIVENESS OF NON-AGGLOMERATED AND AGGLOMERATED IRON ORE EXPORTS AND THEIR CONCENTRATES IN BRAZIL: 2004 TO 2018}

\begin{abstract}
The present study proposes to evaluate of the exporting performance of non-agglomerated and agglomerated iron ore segment as well as their concentrates in Brazil and to identify the sources of growth of Brazilian exports of these products during the time frame of 2004 to 2018. To that end, the indexes of revealed comparative advantage, of revealed symmetric comparative advantage, and of Vollrath's revealed comparative advantage and the Constant-Market-Share model were used, the latter took three subperiods into consideration: 2004-2008; 2009-2013; and 2014-2018. The results indicate that the States of Minas Gerais and Pará exhibited comparative advantage in relation to Brazil regarding non-agglomerated iron ores during the whole analyzed time frame. As for agglomerated iron ores, there is a comparative advantage of the state of Espírito Santo in relation to Brazil, but the same does not occur for the state of Minas Gerais. With regard the sources of growth, one may observe that the growth of the world trade effect negatively affected exports of ferrous ores in the third subperiod compared to the second. In turn, the destination of exports effect was the one that most contributed when comparing the third with the second subperiod, in both segments, as well as the competitiveness effect, which although it was low, was positive in both subperiods for the analyzed commodities.
\end{abstract}

Keywords: International trade. Iron ores. Revealed comparative advantages. Constant-Market-Share.

\footnotetext{
${ }^{1}$ Universidade Regional do Cariri (Urca). Crato/CE, Brasil.

${ }^{2}$ Autora correspondente. Universidade Regional do Cariri (Urca). Rua Antônio Luiz, no 1167 - Pimenta. Crato/CE, Brasil. CEP 63105000. http://lattes.cnpq.br/9139125336083863. https://orcid.org/0000-0003-4088-0754. pinheiroeliane@hotmail.com
} 
A importância das substâncias metálicas na indústria mineral brasileira remonta aos tempos da Colônia, em que as incursões dos bandeirantes em busca de metais preciosos estabeleceram novas rotas para a ocupação do interior do Brasil e culminaram com a exploração de ouro, inicialmente na região de Minas Gerais. Ao longo da história, à medida que a ocupação do território e o conhecimento geológico cresceram, surgiram novas descobertas de depósitos minerais metálicos e substâncias, como o manganês e o ferro, que passaram a desempenhar maior relevância. Essas descobertas impactaram a economia nacional e foram imprescindíveis para fomentar o processo de industrialização brasileiro, conforme Pinheiro, Ferreira Filho e Neves (2016).

Segundo o Instituto Brasileiro de Mineração (IBRAM, 2015), o Brasil possui um território com extensão continental e expressiva diversidade geológica propícia à presença de jazidas de vários minerais, o que conquistou posição de destaque no cenário global. Um dado que atesta a importância do setor extrativo mineral para o Brasil é que, conforme o Informe Mineral da Agência Nacional de Mineração (ANM, 2018), no primeiro semestre de 2018 esse setor registrou um aumento de postos de trabalho, seguindo a retomada do crescimento do mercado de trabalho na economia brasileira, gerando 1.251 postos de trabalho, posto que a extração de minério de ferro foi responsável por 673 destes postos.

Em relação ao comércio exterior, o minério de ferro foi responsável por $64,2 \%$ do valor exportado pela indústria extrativa mineral no primeiro semestre de 2018 (ANM, 2018). Para Black e Avila (2013), dentre os nove principais produtos da pauta exportadora brasileira, em 2011, o minério de ferro destacava-se como o primeiro, contribuindo com $16,3 \%$ das exportações totais brasileiras.

Dentre os principais minerais (minério de ferro, de cobre, de manganês, de alumínio e de cobalto) da pauta de exportações brasileiras, dados do Ministério da Indústria, Comércio Exterior e Serviços (MDIC, 2019) permitem inferir que, no ano de 2018, o minério de ferro foi responsável por $86 \%$ das exportações destas commodities.

Dados do MDIC (2019) apontam também que as vendas externas de minérios de ferro não aglomerados e seus concentrados do país atingiram US\$ 1,47 bilhões em dezembro de 2018. Em dezembro de 2004, as exportações desse produto, em valores de dezembro de 2018, eram aproximadamente de US\$260,89 milhões. Em relação ao volume exportado, passaram de 194,19 bilhões de toneladas, em 2004, para 355,07 bilhões de toneladas, em 2018.

Utilizando essa mesma base de dados, o valor exportado de minérios de ferro aglomerados e seus concentrados enviados do Brasil para o mercado internacional passou de US\$155,75 milhões, em dezembro de 2004 (com valores de dezembro de 2018), para US\$ 354,5 milhões em dezembro de 2018. Quanto ao volume exportado, passaram de 47,24 bilhões de toneladas, em 2004, para 34,73 bilhões de toneladas, em 2018.

Em termos comparativos com o Brasil, dados do MDIC (2019) indicam que, dos US\$16,71 bilhões referentes às exportações brasileiras de minérios de ferro não aglomerados e seus concentrados, em 2018, US\$15,94 bilhões foram advindos dos Estados de Minas Gerais e Pará, isto é, esses dois Estados brasileiros concentraram 95,4\% do valor gerado pelas exportações deste produto. O Estado de Minas Gerais também se destacou no volume exportado de minérios de ferro aglomerados e seus concentrados em 2018, e o Estado do Espírito Santo liderou o ranking 
de maior exportador deste produto. Esses dois Estados foram responsáveis por todo o valor exportado brasileiro de US\$ 3,43 bilhões em 2018.

Diante do papel essencial desempenhado pelos minérios de ferro não aglomerados e aglomerados e seus concentrados no Brasil, torna-se relevante mensurar o desempenho exportador desse segmento para esses Estados. Segundo Coronel, Sousa e Amorim (2011), esse tipo de pesquisa torna-se relevante no sentido de fornecer subsídios ao setor quanto à permanência ou expansão da participação brasileira no mercado internacional, ou seja, contribui para a criação de políticas que fortaleçam o Brasil a competir no mercado externo.

Embora esse segmento seja tão importante para a geração de divisas para o país, estudos a esse respeito ainda são pouco explorados na literatura, podendo-se citar Martins et al. (2010), Pais, Gomes e Coronel (2012), Lopes, Silva e Coronel (2013), Lopes et al. (2014), Franck et al. (2015) e Dórea et al. (2015).

Dentre esses estudos, apenas Pais, Gomes e Coronel (2012) empregaram o Constant-Market-Share (CMS) para o período que antecede a crise financeira internacional. Neste estudo considerou-se esse modelo para o período de 2004 a 2018, permitindo captar as fontes de crescimento de suas exportações brasileiras no período mais recente. Outras inovações adotadas referem-se à utilização do Índice de Vantagem Comparativa Revelada de Vollrath (RCAV) e analisar a competitividade dos minérios de ferro de forma desagregada para não aglomerados e aglomerados. Ademais, foram considerados os principais Estados brasileiros exportadores. A esse respeito, Martins et al. (2010) e Dórea et al. (2015) focaram a análise somente no Estado de Minas Gerais. Este estudo busca, portanto, colaborar com esses enfoques diferenciados em relação às pesquisas realizadas.

Posto isto, este artigo propõe-se a analisar a competitividade das exportações de minérios de ferro não aglomerados e aglomerados e seus concentrados no Brasil e identificar as fontes de crescimento das exportações brasileiras dessas commodities por meio do modelo Constant-Market-Share (CMS) considerando os subperíodos de 2004 a 2008, 2009 a 2013 e 2014 a 2018.

Além dessa seção introdutória, o artigo contém mais cinco seções. O embasamento teórico está descrito na segunda e os estudos empíricos sobre a competitividade das exportações brasileiras de minérios são mostrados na terceira. Em seguida, os procedimentos metodológicos são apresentados. Na quinta seção os resultados são discutidos e confrontados com a literatura, enquanto as considerações finais são expostas na última seção.

\section{REFERENCIAL TEÓRICO}

O comércio, em suas vertentes, como atividade, acompanha o ser humano desde o início da civilização. Nesse aspecto, conhecer o comércio internacional é sumariamente importante para compreender os elementos que permearam o desenvolvimento desta atividade econômica em conformidade com Davanzo et al. (2017). O debate acerca do comércio internacional é um ponto antigo e controverso, possuindo desenvolvimento paralelo às Ciências Econômicas, iniciando com os mercantilistas, passando pelos clássicos e neoclássicos. Em meio a isso, é fundamental entender os determinantes deste tipo de comércio, compreendendo as razões para sua existência (OLIVEIRA, 2007). 
Nessa linha, é relevante destacar autores como Adam Smith, David Ricardo, ditos clássicos, Eli F. Heckscher e Bertil G. Ohlin, identificados como neoclássicos, e suas contribuições à Teoria do Comércio Internacional. Antes do paradigma clássico, o mercantilismo defendia a riqueza por meio da acumulação, e como argumento principal acerca da economia internacional acentuava que os processos de produção e exportação deveriam ser subsidiados pelo Estado e os processos relativos às importações deveriam ser alvo de medidas protecionistas, desestimulando-as (CASSANO, 2002).

Segundo Moreira (2012), como crítica ao protecionismo mercantilista e apologia à divisão do trabalho, nasceu o pensamento liberal clássico do comércio internacional. Adam Smith, influenciado principalmente por David Hume, contrapôs a visão mercantilista de que o comércio mundial era um jogo de soma zero e focou suas análises nas trocas internacionais, em consonância com Oliveira (2007). Vale ressaltar que os economistas clássicos foram responsáveis pela elaboração da teoria do valor-trabalho, considerando o trabalho elemento uniformizador das trocas. Ainda de acordo com Oliveira (2007), a obra prima de Smith, A Riqueza das Nações (1776), evidenciou a especialização social do trabalho como ponto fundamental da produtividade do trabalho na economia e, por conseguinte, da riqueza por bens materiais. Com essa visão de riqueza, Adam Smith pontuou que o comércio com outros países traz bem-estar à sociedade na medida em que permite adquirir produtos que aumentam sua satisfação, e essas trocas internacionais são fundamentadas na ideia de Vantagem Absoluta.

Com esse raciocínio, Smith evidenciou que as trocas entre os países poderiam beneficiar a todos. Dito de outra forma, os países deveriam concentrar sua produção naqueles itens que possuíssem vantagem absoluta e comercializar entre si. Nesse ponto, compreende-se por vantagem absoluta a capacidade de um país produzir bens com menos recursos que outros, podendo lucrar com exportações e importar itens que outros países produzem com menos recursos que este (CASSANO, 2012). Para Esperança, Lírio e Mendonça (2011), a Teoria Clássica das Vantagens Absolutas considerava, em essência, os custos produtivos como fatores determinantes do comércio entre as nações.

Em 1817 o economista inglês David Ricardo publicou o livro Princípios de Economia Política e Tributação, no qual apresentou avanços na teoria de Smith, expondo a sua lei das Vantagens Comparativas, argumentado que, mesmo havendo desvantagem absoluta entre os dois bens produzidos pelos países, seria vantajoso o fluxo de comércio entre ambos (LOPES et al., 2014). De acordo com Coutinho et al. (2005), a vantagem relativa diz respeito à relação entre as quantidades de um determinado produto que dois países abririam mão de produzir direcionando a produção para outro produto. Ou seja, seria interessante que os países se especializassem na produção de bens nos quais possuem vantagem comparativa.

As teorias de cunho clássico, todavia, não conseguem explicar o comércio internacional com precisão, abrindo espaço às novas teorias nesse campo da ciência. Neste ínterim, é oportuno ressaltar os trabalhos desenvolvidos por Eli F. Heckscher e Bertil G. Ohlin. Esse arcabouço, denominado de teoria do comércio neoclássica, apresenta como ideia central que o comércio exterior pode ser explicado pela distinção de dotação entre os fatores produtivos entre os países que comercializam, o que implica que estes buscam exportar os bens cuja produção depende de sua abundância de insumos, como terra, trabalho e capital, da mesma forma que tenderiam a importar produtos cujos insumos de sua produção são escassos no país (MOREIRA, 2012). Corroborando este argumento, Oliveira (2007) destaca que as trocas internacionais são 
vistas como trocas de fatores abundantes por escassos e isso desencadeia um processo no comércio internacional, no qual a mobilidade de bens torna-se substituta da mobilidade de fatores de produção entres os países.

Cabe salientar que, conforme Esperança, Lírio e Mendonça (2011), estas abordagens teóricas são extremamente importantes para a compreensão dos pilares fundamentais da economia internacional, uma vez que expressaram, de forma pertinente, as relações entre as nações. Estes autores ainda pontuam que, dado o grau de desenvolvimento dos países, onde as relações econômicas tornaram-se mais complexas, é necessário apresentar outros fatores que expliquem a competitividade, como a tecnologia. A partir disto, pode-se perceber que aquilo que o comércio internacional define como competitividade possui um significado além da dotação de fatores, mencionada na abordagem de Heckscher-Ohlin e da vantagem comparativa (MARTINS et al., 2010).

Ainda nessa linha, Lopes et al. (2005) reforçam que as abordagens tradicionais do comércio não conseguem explicar os fluxos econômicos em mercados imperfeitos, uma vez que não consideram as estratégias das empresas, o grau de tecnologia, o processo de aperfeiçoamento dos fatores, a globalização, que permitem as economias se relacionarem em cadeia no mercado mundial. Tripoli e Prates (2015) salientam que outra dificuldade encontrada nos modelos de Ricardo e Heckscher-Ohlin é a aplicação empírica. Nesse cenário, nasce a Teoria da Vantagem Competitiva, expressando uma teoria que explora, com maior profundidade, a competição, relacionando os efeitos da economia internacional com a organização industrial.

Porter (1993) procurou elucidar uma abordagem concentrada principalmente na teoria da vantagem competitiva. Em seu trabalho, intitulado A Vantagem Competitiva das Nações, refletiu acerca dos conceitos de competição, mercados segmentados, diferenciação de produtos, papel tecnológico e economia de escalas (COUTINHO et al., 2005). Ademais, estão os fatores denominados por Porter (1993) de "diamante", que Lopes et al. (2005) resumiram como condições de demanda de produtos, oferta de insumos, estrutura do mercado e concorrência entre as empresas.

Adicionado a isso, Franck et al. (2015) assinalaram que a vantagem competitiva é baseada na produtividade, em economias de escala, diferenciação de produtos e processos tecnológicos. Isso significa que o comércio internacional corrobora o aumento da produtividade econômica e elimina a carência da produção de todos os bens dentro do país.

No que se refere à literatura acerca da competitividade, Coutinho e Ferraz (1993) esclarecem a existência de uma gama variada de métodos para avaliá-la. Considerando a construção de indicadores de competitividade, estes autores argumentam que existe uma quantidade ainda mais vasta de abordagens, uma vez que, mesmo aqueles que compartilham visões semeIhantes competitivamente, podem mensurar de forma diferente.

Quanto aos indicadores de competitividade, Almeida et al. (2007) classificaram estes em três óticas: indicadores de desempenho, que focam como a competitividade internacional se apresenta com relação ao mercado internacional; indicadores de eficiência, que necessitam identificar os preços e custos de bens e serviços transacionados relacionando com a produtividade técnica e econômica no uso de insumos produtivos; e indicadores de capacitação, que estão ligados ao sucesso da competição quando adicionados os aspectos tecnológicos, ganhos 
acumulados derivados das formas de organização das empresas, processo cooperativo entre as firmas e aspectos relativos ao investimento nas vertentes públicas e privadas.

\section{REVISÃO DE LITERATURA}

A competitividade das exportações brasileiras tem sido amplamente discutida na literatura econômica para diversos produtos. Como descrito, porém, poucos estudos abordaram especificamente os minérios, podendo citar Martins et al. (2010), Pais, Gomes e Coronel (2012), Lopes, Silva e Coronel (2013), Lopes et al. (2014), Franck et al. (2015), Dórea et al. (2015) e Pereira, Fernandes e Pena (2017), posto que o primeiro considerou o capítulo 26 da Nomenclatura Comum do Mercosul (NCM), que diz respeito aos minérios, escórias e cinzas, enquanto os demais trataram de minério de ferro, que é o objeto de estudo deste artigo.

Martins et al. (2010) empregaram os índices de Vantagem Comparativa Revelada (IVCR), Vantagem Comparativa Revelada Simétrica (IVCRS), Contribuição ao Saldo Comercial (CSC), Taxa de Cobertura (TC), Concentração das Exportações e Comércio Intraindústria para mensurar o desempenho exportador de 12 setores da economia de Minas Gerais nos anos de 1996 a 2008. Os Índices de Vantagens Comparativas Reveladas e Simétrica apresentaram vantagens comparativas para o segmento mencionado. Pais, Gomes e Coronel (2012) analisaram o comportamento das exportações brasileiras de minério de ferro de 2000 a 2008, utilizando o Índice de Orientação Regional (IOR), Vantagem Comparativa Revelada (IVCR) e Constant-Market-Share (CMS). No tocante ao Índice de Vantagem Comparativa Revelada, o minério de ferro apresentou vantagem comparativa forte. Em relação aos resultados do modelo CMS, constataram que o efeito crescimento do comércio mundial foi o que mais contribuiu para o aumento das exportações do mineral durante o período investigado.

Lopes, Silva e Coronel (2013) buscaram verificar o comportamento do mercado exportador brasileiro de minério de ferro para a China, União Europeia (UE), Japão e Coreia do Sul no período de 1999 a 2012 por meio do Índice de Orientação Regional. Os resultados indicaram que as exportações brasileiras de minério de ferro foram orientadas para esses destinos ao longo do período analisado, com exceção da União Europeia a partir de 2009. Lopes et al. (2014) utilizaram o Índice de Orientação Regional e Índice de Vantagem Comparativa Revelada para analisar o comportamento exportador do mercado brasileiro de soja em grão e minério de ferro para a China no período de 1990 a 2012. Este estudo mostrou vantagem comparativa revelada forte nas exportações brasileiras de minério de ferro para a China. Franck et al. (2015) avaliaram a competitividade do mercado exportador australiano e brasileiro de minério de ferro para a China para o período de 1999 a 2014, mediante o Coeficiente de Dependência das Importações (CDI) e o Índice de Orientação Regional (IOR). Os resultados mostraram que as exportações australianas são mais orientadas à China do que as exportações brasileiras. Dórea et al. (2015) investigaram a competitividade da produção de minério de ferro em Minas Gerais nos anos de 1997 a 2014, considerando o Indicador de Vantagem Comparativa Revelada (IVCR) e a Taxa de Cobertura (TC) e constataram que o Estado apresentou vantagem comparativa revelada no período analisado. Pereira, Fernandes e Pena (2017) utilizaram a matriz de competitividade para analisar a inserção externa do Brasil quanto ao desempenho da atividade exportadora no setor de minérios de ferro e seus concentrados, e verificaram um declínio da participação das suas exportações brasileiras de 2015 para 2016. 
ANÁLISE DA COMPETITIVIDADE DAS EXPORTAÇÕES DE MINÉRIOS DE FERRO NÃO AGLOMERADOS E AGLOMERADOS E SEUS CONCENTRADOS NO BRASIL: 2004 A 2018

Manoel Alexandre de Lucena - Eliane Pinheiro de Sousa

O Quadro 1 sintetiza os estudos sobre a competitividade das exportações brasileiras de minérios, empregando indicadores de desempenho.

Quadro 1 - Sínteses dos estudos empíricos

\begin{tabular}{|c|c|c|c|c|c|}
\hline Autores & País/Estado & Período & Produtos & Métodos & Resultados \\
\hline $\begin{array}{l}\text { Martins et al. } \\
\quad(2010)\end{array}$ & $\begin{array}{l}\text { Minas } \\
\text { Gerais }\end{array}$ & $\begin{array}{c}1996 a \\
2008\end{array}$ & $\begin{array}{c}12 \text { setores da } \\
\text { economia, } \\
\text { incluindo } \\
\text { minérios, escórias } \\
\text { e cinzas }\end{array}$ & $\begin{array}{l}\text { IVCR, IVCRS, CSC, } \\
\text { TC, Concentração } \\
\text { das exportações } \\
\text { e Comércio } \\
\text { Intraindústria }\end{array}$ & $\begin{array}{l}I V C R>4, \text { nos anos } \\
2000 \text { a } 2003 \text { e } \\
2<I V C R \leq 4 \text { no } \\
\text { restante da série } \\
0<I V C R S<1\end{array}$ \\
\hline $\begin{array}{l}\text { Pais; Gomes; } \\
\text { Coronel (2012) }\end{array}$ & Brasil & $\begin{array}{c}2000 a \\
2008\end{array}$ & Minério de ferro & IOR, IVCR e CMS & $\begin{array}{l}\text { Orientada para a } \\
\text { China } I V C R>4 \text {; } \\
\text { Efeito crescimento do } \\
\text { comércio mundial. }\end{array}$ \\
\hline $\begin{array}{l}\text { Lopes; Silva; } \\
\text { Coronel (2013) }\end{array}$ & Brasil & $\begin{array}{c}1999 a \\
2012\end{array}$ & Minério de ferro & IOR & $\begin{array}{l}\text { Orientada para a } \\
\text { China, UE, Japão e } \\
\text { Coreia do Sul, exceto } \\
\text { UE a partir de } 2009 .\end{array}$ \\
\hline $\begin{array}{l}\text { Lopes et al. } \\
\text { (2014) }\end{array}$ & Brasil & $\begin{array}{c}1990 \mathrm{a} \\
2012\end{array}$ & $\begin{array}{l}\text { Soja em grão e } \\
\text { minério de ferro }\end{array}$ & IOR e IVCR & $\begin{array}{l}\text { Minério de ferro: } \\
\text { orientada para a China } \\
\text { e } I V C R>4\end{array}$ \\
\hline $\begin{array}{l}\text { Franck et al. } \\
\text { (2015) }\end{array}$ & $\begin{array}{l}\text { Brasil e } \\
\text { Austrália }\end{array}$ & $\begin{array}{c}1999 a \\
2014\end{array}$ & Minério de ferro & CDI e IOR & $\begin{array}{c}\text { Exportações } \\
\text { australianas são mais } \\
\text { orientadas à China do } \\
\text { que as brasileiras. }\end{array}$ \\
\hline $\begin{array}{c}\text { Dórea et al. } \\
\text { (2015) }\end{array}$ & $\begin{array}{l}\text { Minas } \\
\text { Gerais }\end{array}$ & $\begin{array}{c}1997 a \\
2014\end{array}$ & Minério de ferro & IVCR e TC & $\begin{array}{l}I V C R>4, \text { nos } \\
\text { anos } 2000 \text { a } 2003 \text { e } \\
2<I V C R \leq 4 \text { no } \\
\text { restante da série. }\end{array}$ \\
\hline $\begin{array}{c}\text { Pereira; } \\
\text { Fernandes; } \\
\text { Pena (2017) }\end{array}$ & Brasil & $\begin{array}{l}2015- \\
2016\end{array}$ & Minério de ferro & $\begin{array}{c}\text { Matriz } \\
\text { competitividade }\end{array}$ & $\begin{array}{c}\text { Exportações brasileiras } \\
\text { dinâmicas, mas não } \\
\text { competitivas. }\end{array}$ \\
\hline
\end{tabular}

Fonte: Organizado pelos autores.

Conforme se verifica, nenhum desses estudos analisou a competitividade dos minérios de ferro de forma desagregada para não aglomerados e aglomerados, nem utilizou o Índice de Vantagem Comparativa Revelada de Vollrath (RCAV). Essas lacunas são preenchidas neste artigo. Ademais, reitera-se que, dentre a literatura citada no Quadro 1, somente Pais, Gomes e Coronel (2012) utilizaram o modelo Constant-Market-Share (CMS), à medida que Martins et al. (2010) e Dórea et al. (2015) consideraram o Estado de Minas Gerais. Além desse Estado, o presente trabalho também contemplou o Pará para o segmento de não aglomerados e seus concentrados, e o Estado do Espírito Santo para os aglomerados e seus concentrados.

\section{METODOLOGIA}

\section{Índice de Vantagem Comparativa Revelada (IVCR)}

Inspirado na teoria das vantagens comparativas de Ricardo, o Índice de Vantagem Comparativa Revelada (IVCR) foi introduzido por Balassa (1965) a partir de sua constatação acerca 
das dificuldades de mensuração dos fatores relativos à vantagem comparativa entre os países. Nessa linha, tal autor sugere que o estudo dessas vantagens seja realizado de maneira que estas se "revelem" no padrão do comércio.

Em consonância com a literatura, empregou-se o Índice de Vantagem Comparativa Revelada (IVCR), ou Indicador de Balassa (1965). Pode-se calculá-lo pela equação (1):

$I V C R_{i}=\frac{x_{i j} / x_{j}}{x_{w i} / x_{w}}$ (1), em que: $i=$ produto analisado; $X_{i j}=$ valor das exportações do produto $i$ no Estado $j ; X_{j}=$ valor das exportações do Estado $j ; X_{w i}=$ valor total das exportações brasileiras do produto $i ; X_{w}=$ valor total das exportações brasileiras.

Para fins de classificação deste indicador, adotaram-se os procedimentos de Hinloopen e Marrewijk (2001), a saber: se $0<I V C R \leq 1$, o país ou Estado em questão não possui vantagem comparativa revelada; se $1<I V C R \leq 2$, possui vantagem comparativa fraca; se $2<I V C R \leq 4$ , apresenta vantagem comparativa média; e se $I V C R>4$, ocorre vantagem comparativa forte.

Lederman, Olarreaga e Rubiano (2007) apontaram três problemas metodológicos neste índice: i) existe uma dupla contagem das exportações do setor no país e do país nas exportações mundiais; ii) por ser baseado nas exportações líquidas, captura também o comércio intraindústria; e iii) trata-se de um índice assimétrico, uma vez que varia de zero a infinito, todavia, de zero a 1 responde com desvantagem comparativa, e entre 1 e infinito resulta em vantagem.

\section{Índice de Vantagem Comparativa Revelada Simétrica (IVCRS)}

A limitação do IVCR, apontada por Lederman, Olarreaga e Rubiano (2007), quanto ao fato de ser assimétrico, pode ser resolvida empregando o Índice de Vantagem Comparativa Revelada Simétrica (IVCRS). De acordo com a literatura, o IVCRS foi desenvolvido por Laursen (1998) e pode ser computado pela equação (2): $I V C R S_{i}=\frac{I V C R_{i}-1}{I V C R_{i}+1}(2)$

No que se refere à classificação, Martins et al. (2010) e Silva, Silva e Coronel (2017) mostraram que o IVCRS varia de forma linear entre -1 e 1. Quando o índice responder com valores no intervalo entre zero e 1 , significa que o produto possui vantagem comparativa revelada; no entanto, caso o IVCRS apresente valor entre -1 e zero, o produto analisado possui desvantagem comparativa revelada.

\section{Índice de Vantagem Comparativa Revelada de Vollrath (RCAV)}

Visando a resolver o problema da dupla contagem do IVCR, indicado por Lederman, Olarreaga e Rubiano (2007), adotou-se o Índice de Vantagem Comparativa Revelada de Vollrath( $R C A V_{i}$ ) recomendado por Bender e Li (2002), sendo expresso pela equação (3):

$R C A V_{i}=\frac{\frac{x_{i j}}{\left(\Sigma_{i} x_{i j}\right)-X_{i j}}}{\frac{\left(\Sigma_{j} x_{i j}\right)-X_{i j}}{\left[\left(\Sigma_{j} \Sigma_{i} x_{i j}\right)-\left(\Sigma_{j} x_{i j}\right)\right]-\left[\left(\Sigma_{i} x_{i j}\right)-X_{i j}\right]}}(3)$, em que: ${ }^{i}=$ produto analisado; $X_{i j}=$ valor das expor-

tações do produto $i$ no Estado $j ; \sum_{i} X_{i j}=$ valor total das exportações do Estado $j ; \sum_{j} X_{i j}=$ valor das exportações brasileiras do produto $i ; \sum_{j} \sum_{i} X_{i j}=$ valor total das exportações brasileiras. 
De acordo com estudos recentes desenvolvidos por Santos e Sousa $(2017,2019)$, se o valor do indicador $R C A V_{i}$ for maior que um, pode-se afirmar que o Estado considerado possui vantagem comparativa revelada de Vollrath na exportação do produto avaliado. Caso contrário, possui desvantagem comparativa revelada de Vollrath.

\section{Constant Market Share}

O método do Constant Market Share (CMS) possibilita determinar os fatores que estão relacionados ao favorecimento das exportações de um determinado país ao longo de um dado período de tempo (SILVA; HIDALGO, 2012). Segundo Carvalho (2004) e Bittencourt, Fontes e Campos (2012), este modelo atribui o crescimento das exportações ao setor exportador, tanto na estrutura das exportações do país quanto em sua competitividade, posto que a sua principal vantagem é possibilitar que a análise do produto no mercado de destino seja decomposta por componentes.

Lima, Lélis e Cunha (2015) afirmam que o CMS adota como pressuposto que o Marke$t$-Share do país, nas suas exportações mundiais, se mantém constante no decorrer do tempo se as suas vendas no comércio internacional crescerem na mesma velocidade e sentido que as exportações mundiais.

Empregando o modelo utilizado por Bittencourt, Fontes e Campos (2012) e Lima, Lélis e Cunha (2015) e proposto inicialmente por Leamer e Stern (1970), define-se: $X^{I}=$ Valor total das exportações brasileiras no período $1 ; X^{I I}=$ Valor total das exportações brasileiras no período 2; $X_{i}^{I}=$ Valor das exportações brasileiras de minério de ferro no período $1 ; X_{i}^{I I}=$ Valor das exportações brasileiras de minério de ferro no período $2 ; X_{j}^{I}=$ Valor das exportações brasileiras para o país $j$ no período $1 ; X_{j}^{I I}=$ Valor das exportações brasileiras para o país $j$ no período $2 ; X_{i j}^{I}=$ Valor das exportações brasileiras para o país $j$ de minério de ferro no período $1 ; X_{i j}^{I I}=$ Valor das exportações brasileiras para o país $j$ de minério de ferro no período $2 ; r=$ Crescimento percentual das exportações mundiais entre os períodos 1 e $2 ; r_{i}=$ Crescimento percentual das exportações mundiais de minério de ferro entre os períodos 1 e $2 ; r_{i j}=$ Crescimento percentual das exportações mundiais de minério de ferro para o país $j$ entre os períodos 1 e 2 .

A primeira formulação deste modelo considera que não existe diferença por produto ou no destino das exportações do país. Assim, pode-se escrever a seguinte identidade:

$X^{I I}-X^{I} \equiv X^{I I}-X^{I}+r X^{I}-r X^{I}(4)$

Reorganizando os termos, obtém-se: $X_{i}^{I I}-X_{i}^{I} \equiv r_{i} X_{i}^{I}+\left(X_{i}^{I I}-X_{i}^{I}-r_{i} X_{i}^{I}\right.$ (5)

A partir da equação (5), podem-se incluir os demais produtos que compõem as exportações (6): $X_{i}^{I I}-X_{i}^{I} \equiv r_{i} X_{i}^{I}+\left(X_{i}^{I I}-X_{i}^{I}-r_{i} X_{i}^{I}\right.$ (6)

Agregando a identidade descrita na equação (7) e somando e subtraindo $r$, expressa-se:

$$
\begin{aligned}
X^{I I}-X^{I} & \equiv \sum r_{i} X_{i}^{I}+\sum\left(X_{i}^{I I}-X_{i}^{I}-r_{i} X_{i}^{I}\right) \\
X^{I I}-X^{I} & \equiv \sum\left(r-r+r_{i}\right) X_{i}^{I}+\sum\left(X_{i}^{I I}-X_{i}^{I}-r_{i} X_{i}^{I}\right) \\
X^{I I}-X^{I} & \equiv \sum r X_{i}^{I}+\sum\left(r_{i}-r\right) X_{i}^{I}+\sum\left(X_{i}^{I I}-X_{i}^{I}-r_{i} X_{i}^{I}\right) \\
X^{I I}-X^{I} & \equiv r X^{I}+\sum_{i}\left(r_{i}-r\right) X_{i}^{I}+\sum_{i}\left(X_{i}^{I I}-X_{i}^{I}-r_{i} X_{i}^{I}\right)
\end{aligned}
$$


Em conformidade com Rodrigues e Arêdes (2017), as variações na taxa de crescimento das exportações de um dado produto são decompostas nos efeitos referentes ao crescimento do mercado mundial, ao destino das exportações e ao efeito competitividade. Na equação (8) tais componentes são identificados como: $\sum_{i} r X_{i}^{I}=$ aumento das exportações mundiais; $\sum_{i}\left(r_{i}-r\right) X_{i}^{I}=$ composição da pauta dos produtos exportados e $\sum_{i}\left(X_{i}^{I I}-X_{i}^{I}-r_{i} X_{i}^{I}\right)=$ efeito competitividade.

\section{Fonte dos Dados}

Este trabalho utilizou dados das exportações de minérios de ferro não aglomerados e seus concentrados, Free on Board (FOB) em dólares, de Minas Gerais e Pará e das exportações de minérios de ferro aglomerados e seus concentrados, Free on Board (FOB) em dólares, de Minas Gerais e Espírito Santo, obtidos junto ao Comex Stat do Ministério da Indústria, Comércio Exterior e Serviços (MDIC, 2019), e dados, em dólares, de suas importações e exportações mundiais, junto ao United Nations Commodity Trade Statistics Database (UN Comtrade) (INTERNATIONAL TRADE..., 2020) para o período de 2004 a 2018. No que diz respeito à identificação do produto, empregou-se o código da Nomenclatura Comum do Mercosul (NCM), com seis dígitos no que se refere aos minérios de ferro aglomerados e seus concentrados (NCM 260112) e minérios de ferro não aglomerados e seus concentrados (NCM 260111).

Como as exportações modificam-se no decorrer do tempo, conforme Coronel, Machado e Carvalho (2009), deve-se realizar a análise em períodos mais curtos, permitindo captar tais alterações com mais segurança. Seguindo essa proposta, o período de 2004 a 2018 foi desagregado nos seguintes subperíodos: 2004 a 2008, que representa o período que antecedeu a crise financeira internacional de 2008, 2009 a 2013, que indica a fase pós-crise, e 2014 a 2018, que corresponde ao período mais recente das exportações de minérios de ferro não aglomerados, aglomerados e seus concentrados.

\section{ANÁLISE E DISCUSSÃO DOS RESULTADOS}

\section{Balança Comercial Brasileira de Minério de Ferro}

Os dados expostos na Tabela 1 atestam a importância destas commodities para o comércio brasileiro, uma vez que a série apresentou superávit na balança comercial em todos os anos analisados. De 2004 a 2008 infere-se um progressivo crescimento das exportações de minérios de ferro. Segundo o Informe Mineral do Departamento Nacional de Produção Mineral (DNPM, 2009), esses resultados podem ser atribuídos a um ciclo de prosperidade na economia mineral iniciado a partir de 2003. A amplitude desse boom ocasionou um aumento de demanda muito acima da oferta, impulsionando o redirecionamento de novos capitais para a área. O mesmo Informe pontua que esse novo ciclo na economia mineral rompeu um paradigma que apontava o descrédito nesse mercado, principalmente de minérios de ferro. 
ANÁLISE DA COMPETITIVIDADE DAS EXPORTAÇÕES DE MINÉRIOS DE FERRO NÃO AGLOMERADOS E AGLOMERADOS E SEUS CONCENTRADOS NO BRASIL: 2004 A 2018

Manoel Alexandre de Lucena - Eliane Pinheiro de Sousa

Tabela 1 - Balança comercial brasileira de minérios de ferro não aglomerados e aglomerados e seus concentrados no período de 2004 a 2018 (em US\$ FOB)

\begin{tabular}{c|c|c|c|c|c|c}
\hline \multirow{2}{*}{ Ano } & \multicolumn{3}{|c|}{ Não aglomerados } & \multicolumn{3}{c|}{ Aglomerados } \\
\cline { 2 - 7 } & $\mathrm{X}$ & $\mathrm{M}$ & $\mathrm{X}-\mathrm{M}$ & $\mathrm{X}$ & $\mathrm{M}$ & $\mathrm{X}-\mathrm{M}$ \\
\hline 2004 & 3.042 .387 .419 & 3.343 & 3.042 .384 .076 & 1.716 .487 .798 & 1.725 .859 & 1.714 .761 .939 \\
2005 & 4.434 .980 .083 & 40.782 & 4.434 .939 .301 & 2.861 .660 .019 & 2.043 & 2.861 .657 .976 \\
2006 & 5.750 .495 .851 & 19.242 & 5.750 .476 .609 & 3.198 .375 .466 & 0 & 3.198 .375 .466 \\
2007 & 7.114 .106 .951 & 43.121 & 7.114 .063 .830 & 3.443 .804 .503 & 0 & 3.443 .804 .503 \\
2008 & 11.053 .596 .434 & 25.753 & 11.053 .570 .681 & 5.484 .825 .164 & 9.989 .482 & 5.474 .835 .682 \\
2009 & 10.582 .192 .295 & 7.858 .431 & 10.574 .333 .864 & 2.657 .571 .175 & 0 & 2.657 .571 .175 \\
2010 & 21.353 .877 .790 & 13.795 .970 & 21.340 .081 .820 & 7.513 .841 .843 & 2.345 & 7.513 .839 .498 \\
2011 & 31.851 .759 .654 & 5.954 & 31.851 .753 .700 & 9.965 .454 .201 & 6.099 & 9.965 .448 .102 \\
2012 & 23.809 .804 .469 & 57.159 & 23.809 .747 .310 & 7.179 .488 .036 & 0 & 7.179 .488 .036 \\
2013 & 25.996 .245 .937 & 6.259 & 25.996 .239 .678 & 6.495 .284 .794 & 688 & 6.495 .284 .106 \\
2014 & 19.982 .659 .631 & 96.768 & 19.982 .562 .863 & 5.836 .430 .545 & 383 & 5.836 .430 .162 \\
2015 & 10.339 .928 .216 & 4.467 & 10.339 .923 .749 & 3.697 .175 .407 & 1.939 & 3.697 .173 .468 \\
2016 & 11.575 .969 .998 & 5.366 & 11.575 .964 .632 & 1.713 .370 .778 & 0 & 1.713 .370 .778 \\
2017 & 16.712 .952 .368 & 3.641 & 16.712 .948 .727 & 2.486 .201 .832 & 521 & 2.486 .201 .311 \\
2018 & 16.714 .107 .425 & 6.067 & 16.714 .101 .358 & 3.501 .554 .965 & 3.965 & 3.501 .551 .000 \\
\hline
\end{tabular}

Nota: (X) - Valores das exportações; (M) - Valores das importações; (X- M) - Saldo da balança comercial.

Fonte: Elaborada pelos autores a partir de dados do MDIC (2019).

O ano de 2009 é marcado pelos efeitos advindos da crise de 2008, também chamada de crise do subprime. Tal evento afetou diretamente o comércio mundial e, por conseguinte, a balança comercial brasileira. Identifica-se, portanto, uma queda nas exportações brasileiras de minérios de ferro em ambos os segmentos analisados em 2009. O estudo de Dórea et al. (2015) corrobora esse resultado.

No período pós-crise até o ano de 2013, observam-se oscilações das exportações deste item, mas com um crescimento relativo, que pode ser atribuídos à recuperação do comércio internacional. Os anos de 2014 e 2015 interrompem esse ciclo, apresentando queda mais expressiva, conforme a Tabela 1. Segundo o Informe Mineral (DNPM, 2015), o fator que explica essa retração é a queda do preço médio dos minérios de ferro no exterior, o que eleva, em contrapartida, a quantidade exportada. Esse preço recupera-se somente a partir de 2016, quando já se observa uma tênue melhora nas exportações.

Os dois anos finais da série mostram leve recuperação das exportações de minérios de ferro não aglomerados e aglomerados. Tal situação pode ser revertida especialmente por conta da China, principal importadora de minérios de ferro brasileiro, que tem apresentado índices de taxas de crescimento menores, o que é refletida em uma queda na sua participação nesse setor no primeiro semestre de 2018 em relação a 2017, conforme o Informe Mineral (ANM, 2018). 


\section{Índice de Vantagem Comparativa Revelada (IVCR)}

O índice de vantagem comparativa revelada (IVCR) para as exportações mineiras de minérios de ferro não aglomerados e aglomerados é representado na Tabela 2. Além do Estado de Minas Gerais, essa tabela também expõe os resultados do IVCR para os Estados do Pará e do Espírito Santo, respectivamente, para os segmentos não aglomerados e aglomerados.

Tabela 2 - Índice de vantagem comparativa revelada para as exportações de minérios de ferro não aglomerados e aglomerados no período de 2004 a 2018

\begin{tabular}{c|c|c|c|c}
\hline \multirow{2}{*}{ Ano } & \multicolumn{2}{|c|}{ Minérios de ferro não aglomerados } & \multicolumn{2}{c}{ Minérios de ferro aglomerados } \\
\cline { 2 - 5 } 2004 & Minas Gerais & Pará & Minas Gerais & Espírito Santo \\
2005 & 6,13 & 8,39 & 0,01 & 20,45 \\
2006 & 5,70 & 8,12 & 0,00 & 18,81 \\
2007 & 5,50 & 7,08 & 0,07 & 18,69 \\
2008 & 5,70 & 6,59 & 0,27 & 19,68 \\
2009 & 5,04 & 6,44 & 0,34 & 16,39 \\
2010 & 4,79 & 6,60 & 0,32 & 21,76 \\
2011 & 3,94 & 5,08 & 0,46 & 14,18 \\
2012 & 3,66 & 5,16 & 0,39 & 14,40 \\
2013 & 4,33 & 6,05 & 0,35 & 17,49 \\
2014 & 4,33 & 5,79 & 0,68 & 20,08 \\
2015 & 4,52 & 5,90 & 0,62 & 16,26 \\
2016 & 5,19 & 7,14 & 0,65 & 17,97 \\
2017 & 4,87 & 7,29 & 1,25 & 24,13 \\
2018 & 4,26 & 7,00 & 1,38 & 22,75 \\
\hline Média & 4,04 & 8,46 & 1,55 & 22,50 \\
\hline TAC & 4,80 & 6,74 & 0,56 & 19,04 \\
\hline
\end{tabular}

Nota: TAC - Taxa média anual de crescimento.

Fonte: Elaborada pelos autores a partir de dados do MDIC (2019).

No que se refere ao segmento não aglomerado, os Estados de Minas Gerais e Pará apresentaram vantagem comparativa revelada durante todo o período analisado, posto que Minas Gerais alcançou um IVCR médio de 4,8 durante o período, porém registrou decréscimo de $2,47 \%$ ao ano. Com respeito ao Pará, todos os anos da série obtiveram IVCR acima de 4, indicando vantagem comparativa forte, conforme a classificação de Hinloopen e Marrewijk (2001). Seguindo esse critério, o Estado de Minas Gerais não se situou nessa faixa apenas nos anos de $2010 \mathrm{e}$ 2011, quando registrou vantagem comparativa média.

Em consonância com o Informe Mineral (DNPM, 2017), o Pará possui um grande volume de bens minerais, sendo uma atividade importante para a economia, que movimenta a balança comercial do Estado. O documento aponta também que, a partir de 2014, passou-se a direcionar um volume de investimento que se estendeu até 2018, quando, já em 2016, observa-se que a produção de minérios do Estado foi liderada por minério de ferro. Esse fator pode explicar os elevados valores computados pelo IVCR do Pará.

Ainda com respeito aos minérios de ferro não aglomerados, é possível perceber um comportamento decrescente do IVCR de 2004 a 2011. Pais, Gomes e Coronel (2012), ao analisarem 
a competitividade das exportações brasileiras de minérios de ferro para o período de 2000 a 2008, atribuíram esse efeito decrescente do indicador ao crescimento mais que proporcional das exportações mundiais de minérios de ferro ao comparar com exportações do Brasil, e enfatizaram o crescimento das exportações australianas destas commodities. O mesmo efeito foi encontrado por Lopes et al. (2014), ao analisarem a competitividade das exportações brasileiras de soja em grão e de minérios de ferro para a China no período de 1999 a 2012.

Quanto aos minérios de ferro aglomerados exportados por Minas Gerais, o IVCR teve desvantagem comparativa para o período de 2004 a 2015. A situação foi revertida nos últimos três anos da série analisada. À luz, todavia, da classificação adotada, tal reversibilidade ainda se situa em vantagem comparativa revelada fraca, e, em média, esse setor obteve valor de 0,56.

No que se refere ao Espírito Santo, infere-se, a partir da Tabela 2, que esse Estado apresenta vantagem comparativa revelada nas exportações de minérios de ferro aglomerados durante toda a série analisada. Os valores do IVCR foram muito expressivos, e, conforme se observa, atingiu seu maior valor em 2016, com 24,13, registrando média de 19,04 e 2,47\% de crescimento médio anual. Para fins da classificação de Hinloopen e Marrewijk (2001), o presente Estado respondeu com vantagem comparativa forte.

Ainda com relação ao Estado do Espírito Santo e seu alto desempenho exportador, dados do MDIC (2019) atestam que este liderou as exportações de minérios de ferro aglomerados e seus concentrados durante todos os anos abordados neste estudo. Este tipo de segmento mineral - aglomerados - é produzido no processo de pelotização, em que os minérios de ferros finos são aglomerados em pelotas, e, em seguida, endurecidos em fornalhas. Um fator explicativo desse elevado desempenho são os investimentos feitos pela empresa Vale, a maior produtora mundial de mineral ferroso e pelotas de minérios de ferros na sociedade capixaba, conforme o Relatório Anual (Relatório Form 20-F, 2019), em 2018. Esses investimentos, que se materializam em desenvolvimento do segmento mineral, incrementam inovações no produto que se traduzem nas vantagens obtidas no comércio internacional.

\section{Índice de Vantagem Comparativa Revelada Simétrica (IVCRS)}

O índice de vantagem comparativa revelada simétrica (IVCRS) para minérios de ferro não aglomerados e aglomerados é exposto na Tabela 3. Conforme a classificação adotada, o Estado de Minas Gerais apresentou vantagem comparativa revelada para minérios de ferros não aglomerados durante o período de 2004 a 2018, com média do IVCRS de 0,65. Martins et al. (2010) analisaram o desempenho exterior do comércio de Minas Gerais no período de 1996 a 2008 de maneira agregada por capítulo da Nomenclatura Comum do Mercosul (NCM). Os resultados encontrados para o IVCRS para o capítulo 26 (minérios, escórias e cinzas) corroboram os obtidos neste estudo para os minérios de ferro não aglomerados.

Tabela 3 - Índice de vantagem comparativa revelada simétrica para as exportações de minérios de ferro não aglomerados e aglomerados, no período de 2004 a 2018

\begin{tabular}{c|c|c|c|c}
\hline \multirow{2}{*}{ Ano } & \multicolumn{2}{|c|}{ Minérios de ferro não aglomerados } & \multicolumn{2}{c}{ Minérios de ferro aglomerados } \\
\cline { 2 - 5 } & Minas Gerais & Pará & Minas Gerais & Espírito Santo \\
\hline 2004 & 0,72 & 0,79 & $-0,98$ & 0,91 \\
2005 & 0,70 & 0,78 & $-1,00$ & 0,90 \\
2006 & 0,69 & 0,75 & $-0,88$ & 0,90
\end{tabular}




\begin{tabular}{c|l|l|l|l}
\hline 2007 & 0,70 & 0,74 & $-0,57$ & 0,90 \\
2008 & 0,67 & 0,73 & $-0,49$ & 0,88 \\
2009 & 0,65 & 0,74 & $-0,52$ & 0,91 \\
2010 & 0,60 & 0,67 & $-0,37$ & 0,87 \\
2011 & 0,57 & 0,68 & $-0,44$ & 0,87 \\
2012 & 0,62 & 0,72 & $-0,48$ & 0,89 \\
2013 & 0,62 & 0,71 & $-0,19$ & 0,91 \\
2014 & 0,64 & 0,71 & $-0,23$ & 0,88 \\
2015 & 0,68 & 0,75 & $-0,21$ & 0,89 \\
2016 & 0,66 & 0,76 & 0,11 & 0,92 \\
2017 & 0,62 & 0,75 & 0,16 & 0,92 \\
2018 & 0,60 & 0,79 & 0,21 & 0,91 \\
\hline Média & 0,65 & 0,74 & $-0,39$ & 0,90 \\
\hline TAC & $-1,15$ & 0,09 & $-12,81$ & 0,09 \\
\hline
\end{tabular}

Nota: TAC - Taxa média anual de crescimento.

Fonte: Elaborada pelos autores a partir de dados do MDIC (2019).

Considerando o mesmo segmento - minérios de ferro não aglomerados - para o Estado do Pará, verifica-se a presença de vantagem comparativa revelada para todos os anos analisados neste estudo. Comparando com o IVCRS de Minas Gerais, o IVCRS do Pará manteve-se superior por todo o período de 2004 a 2018, refletindo uma maior competitividade das exportações paraenses desse segmento do que a mineira.

No que diz respeito aos minérios de ferro aglomerados, o Estado de Minas Gerais apresentou IVCRS entre -1 e zero para os anos 2004 a 2015, mostrando, assim, que o Estado possui desvantagem comparativa revelada nas exportações deste produto. Os últimos três anos analisados registraram vantagem comparativa revelada. Esse comportamento reversivo das exportações de minérios de ferro aglomerados em Minas Gerais nos últimos anos pode ser atribuído aos investimentos realizados pela empresa Vale, com um montante que ultrapassa $R \$ 10,1$ biIhões no custo e investimentos na área de mineração, que inclui pesquisas e logística no primeiro semestre de 2018 (BALANÇO VALE MAIS, 2018). Tais investimentos possibilitam agregar valor ao segmento mineral exportado, permitindo obter vantagens comparativas bem como competitividade no comércio exterior.

O IVCRS do Espírito Santo para minérios de ferro aglomerados indica que o Estado possui vantagem comparativa revelada nas exportações do produto, uma vez que todos os valores pertencem ao intervalo de zero a 1. Os anos de 2016 e 2017 tiveram os maiores valores, ficando com 0,92, enquanto a média para o indicador foi de 0,9 . Comparando os valores com os demais Estados analisados, quanto ao IVCRS, o Espírito Santo destacou-se com os maiores índices em todos os anos.

\section{Índice de Vantagem Comparativa Revelada de Vollrath (RCAV)}

O índice de vantagem comparativa revelada de Vollrath (RCAV) para as exportações mineiras de minérios de ferro não aglomerados e aglomerados, exibido na Tabela 4, corrobora os resultados encontradas para o IVCR e IVCRS nos dois segmentos analisados. Quanto aos não aglomerados, observa-se vantagem comparativa revelada de Vollrath em Minas Gerais durante todo o período, apesar das trajetórias decrescentes de 2007 a 2011, que podem ser decorrentes 
ANÁLISE DA COMPETITIVIDADE DAS EXPORTAÇÕES DE MINÉRIOS DE FERRO NÃO AGLOMERADOS E AGLOMERADOS E SEUS CONCENTRADOS NO BRASIL: 2004 A 2018

Manoel Alexandre de Lucena - Eliane Pinheiro de Sousa

dos impactos da crise de 2008, e, posteriormente, a partir de 2013, fechando a série em 2018 com o menor valor computado $(8,10)$ para o RCAV.

Tabela 4 - Índice de vantagem comparativa revelada de Vollrath para as exportações de minérios de ferro não aglomerados e aglomerados no período de 2004 a 2018

\begin{tabular}{c|c|c|c|c}
\hline \multirow{2}{*}{ Ano } & \multicolumn{2}{|c|}{ Minérios de ferro não aglomerados } & \multicolumn{2}{c}{ Minérios de ferro aglomerados } \\
\cline { 2 - 4 } & Minas Gerais & Pará & Minas Gerais & Espírito Santo \\
\hline 2004 & 18,48 & 16,05 & 0,01 & 220,40 \\
2005 & 17,93 & 16,15 & 0,00 & 286,68 \\
2006 & 16,59 & 14,18 & 0,06 & 355,39 \\
2008 & 18,96 & 12,69 & 0,25 & 206,04 \\
2009 & 15,92 & 14,03 & 0,31 & 173,75 \\
2010 & 15,56 & 17,13 & 0,28 & 446,77 \\
2011 & 13,87 & 14,04 & 0,41 & 171,72 \\
2012 & 12,93 & 19,42 & 0,34 & 208,17 \\
2013 & 15,17 & 20,71 & 0,31 & 279,82 \\
2014 & 16,46 & 21,44 & 0,64 & 434,61 \\
2015 & 15,29 & 17,42 & 0,58 & 319,07 \\
2016 & 15,46 & 17,25 & 0,62 & 347,56 \\
2017 & 14,11 & 20,69 & 1,30 & 200,20 \\
2018 & 10,59 & 25,26 & 1,46 & 184,15 \\
Média & 8,10 & 41,35 & 1,66 & 185,03 \\
\hline TAC & 15,03 & 19,19 & 0,55 & 267,96 \\
\hline
\end{tabular}

Nota: TAC - Taxa média anual de crescimento.

Fonte: Elaborada pelos autores a partir de dados do MDIC (2019).

No que se refere ao segmento mineral ferroso aglomerado, percebe-se que o Estado de Minas Gerais apresentou vantagem comparativa revelada de Vollrath apenas para 2016, 2017 e 2018. Cabe ressaltar, também, que o ano de 2005 não registrou exportações deste item na pauta do Estado. O RCAV para o Pará, analisado para minérios de ferro não aglomerados e seus concentrados, mostrado na Tabela 4, permite inferir que esse Estado tem se destacado ante as exportações desta commodity, conquistando vantagem comparativa revelada de Vollrath para toda a série analisada, posto que o maior valor $(41,35)$ foi obtido em 2018 , enquanto a taxa média anual de crescimento foi de $9,07 \%$ no período considerado.

Quanto aos minérios de ferro aglomerados e seus concentrados, exportado pelo Espírito Santo, o RCAV mostra o mesmo comportamento do IVCR e do IVCRS. Todos os anos tiveram vantagem comparativa revelada de Vollrath com média de 267,96, atingindo um máximo de 446,77 para o ano de 2009. Constata-se, ainda, um crescimento médio anual do RCAV de 9,07\%. De posse das considerações já apresentadas para o IVCR do Estado, e assentado como fator explicativo de seu forte desempenho relativo ao mineral ferroso aglomerado, Ferreira (2001) já havia pontuado a importância da indústria de pelotização brasileira, mencionando os fatores que destacavam o Brasil como competitivo, a saber: abundância de minério fino e a facilidade de maior possibilidade de enriquecimento do minério de baixo teor. Afirma, ainda, que tal processo industrial agrega mais valor ao componente mineral. Esse conjunto de elementos é o diferencial na mineração do Espírito Santo, que possibilita a competitividade internacional e se revela nas vantagens comparativas. 


\section{Constant Market Share}

Com relação aos valores médios das exportações mundiais e brasileiras de minérios de ferro aglomerados e seus concentrados durante o período de 2004 a 2018, expostos na Tabela 5, o subperíodo I (2004 a 2008) mostra que o Brasil participava com 31,67\% das exportações mundiais, em média, deste segmento mineral. Nos subperíodos II (2009 a 2013) e III (2014 a 2018) observam declínios das participações do Brasil no comércio mundial de minérios de ferro, com valores, respectivamente, de $28,61 \%$ e $21,89 \%$.

Tabela 5 - Valor médio das exportações mundiais e brasileiras de minérios de ferro aglomerados e seus concentrados, em US\$̦, e participação do Brasil nas exportações mundiais de minérios de ferro aglomerados e seus concentrados no período de 2004 a 2018

\begin{tabular}{c|c|c|c}
\hline & $2004 / 2008$ & $2009 / 2013$ & $2014 / 2018$ \\
\hline Exportações mundiais & $10.550 .864 .074,00$ & $23.638 .274 .928,80$ & $15.744 .695 .201,40$ \\
Exportações brasileiras & $3.341 .030 .590,00$ & $6.762 .328 .009,80$ & $3.446 .946 .705,60$ \\
Market Share (\%) & 31,67 & 28,61 & 21,89 \\
\hline
\end{tabular}

Fonte: Elaborada pelos autores a partir de dados do MDIC (2019) e UN Comtrade (INTERNATIONAL TRADE..., 2020).

Essa retração pode ser atribuída ao fato de a China, maior importadora do minério brasileiro, segundo Dórea et al. (2015), ter apresentado crescimento em níveis menores e ter revisto sua política de grande importadora mundial, direcionando a manutenção do crescimento com base no consumo advindo do mercado doméstico. Nessa linha, por meio da decomposição das fontes de crescimento das exportações de minérios de ferro aglomerados, apresentada na Tabela 6 , pode-se constatar tal fato levando em consideração a expressiva redução do comércio mundial desta commodity no período analisado.

Tabela 6 - Fontes de crescimento das exportações de minérios de ferro aglomerados e seus concentrados no período de 2004 a 2018

\begin{tabular}{c|c|c}
\hline $\begin{array}{c}\text { Fontes de crescimento das exportações de } \\
\text { minérios de ferro aglomerados }\end{array}$ & $2004 / 2008$ a 2009/2013 (\%) & $2009 / 2013$ a 2014/2018 (\%) \\
\hline Crescimento do Comércio Mundial & 272,73 & $-3.867,12$ \\
Destino das Exportações & $-208,53$ & $3.921,17$ \\
Competitividade & 35,80 & 45,96 \\
\hline
\end{tabular}

Fonte: Elaborada pelos autores a partir de dados do MDIC (2019) e UN Comtrade (INTERNATIONAL TRADE..., 2020).

Por outro lado, observa-se que o destino das exportações contribuiu fortemente para o comércio externo brasileiro deste segmento mineral, em que sai de -208,53\% para $3.921,17 \%$, atestando a magnitude desse aumento. De acordo com o MDIC (2019), a partir de 2013, além dos países tradicionais importadores do minério de ferro brasileiro - China, Japão e Itália -, começaram a ganhar destaque os Países Baixos, Emirados Árabes, Coreia do Sul, Estados Unidos e Egito. Neste sentido, o efeito competitividade aumentou entre os dois subperíodos analisados em aproximadamente $10 \%$. Segundo Carvalho (2017), o mercado internacional de minério de ferro recente é caracterizado por ser cada vez mais competitivo, sendo formado por quatro maiores produtoras: Vale, BHP, Rio Tinto e Fortescue. Para o autor, estas quatro, especialmente a Vale e Rio Tinto, buscam reduzir seus preços. Tais práticas colaboram para o ganho de competitividade. 
ANÁLISE DA COMPETITIVIDADE DAS EXPORTAÇÕES DE MINÉRIOS DE FERRO NÃO AGLOMERADOS E AGLOMERADOS E SEUS CONCENTRADOS NO BRASIL: 2004 A 2018

Manoel Alexandre de Lucena - Eliane Pinheiro de Sousa

Quanto aos minérios de ferro não aglomerados e seus concentrados, o comportamento das exportações mundiais é similar àquele observado para minérios de ferro aglomerados. Cabe destacar, no entanto, que o subperíodo II (2009 a 2013) apontou um forte crescimento nas exportações mundiais e brasileiras de minérios de ferro não aglomerados e seus concentrados com relação ao subperíodo I (2004 a 2008), saltando de 24,29\% para 25,31\%, conforme a Tabela 7.

Tabela 7 - Valor médio das exportações mundiais e brasileiras de minérios de ferro não aglomerados e seus concentrados, em US\$̦, e participação do Brasil nas exportações mundiais de minérios de ferro não aglomerados e seus concentrados no período de 2004 a 2018

\begin{tabular}{c|c|c|c}
\hline & $2004 / 2008$ & $2009 / 2013$ & $2014 / 2018$ \\
\hline Exportações mundiais & $25.851 .660 .626,80$ & $89.746 .249 .012,80$ & $71.336 .255 .248,80$ \\
Exportações brasileiras & $6.279 .113 .347,60$ & $22.718 .776 .029,00$ & $15.066 .062 .930,40$ \\
Market Share (\%) & 24,29 & 25,31 & 21,12 \\
\hline
\end{tabular}

Fonte: Elaborada pelos autores a partir de dados do MDIC (2019) e UN Comtrade (INTERNATIONAL TRADE..., 2020).

Esse efeito positivo pode ser atribuído à recuperação do comércio mundial no pós-crise, uma vez que, conforme Dórea et al. (2015), a crise de 2008 afetou a balança comercial brasileira ocasionando retração nas exportações de minério de ferro. Para esses autores, observa-se a recuperação no comércio mundial apenas nos anos de 2010 e 2011. Posterior a esse período, a economia mundial enfrentava outro choque negativo decorrente do endividamento dos bancos europeus. O subperíodo III (2014 a 2018) é afetado por este cenário, identificando, assim, uma queda na participação brasileira no comércio mundial do segmento mineral analisado.

Os resultados da Tabela 8 mostram uma expressiva redução do comércio mundial deste produto. $O$ estudo de Pais, Gomes e Coronel (2012) identificou uma redução do efeito comércio mundial de minérios de ferro, considerando o recorte temporal de 2000 a 2008.

Tabela 8 - Fontes de crescimento das exportações de minérios de ferro não aglomerados e seus concentrados no período de 2004 a 2018

\begin{tabular}{c|c|c}
\hline $\begin{array}{c}\text { Fontes de crescimento das exportações } \\
\text { de minérios de ferro não aglomerados }\end{array}$ & 2004/2008 a 2009/2013 (\%) & 2009/2013 a 2014/2018 (\%) \\
\hline Crescimento do Comércio Mundial & 51,11 & $-9.069,26$ \\
Destino das Exportações & $-0,14$ & $9.132,98$ \\
Competitividade & 49,03 & 36,28 \\
\hline
\end{tabular}

Fonte: Elaborada pelos autores a partir de dados do MDIC (2019) e UN Comtrade (INTERNATIONAL TRADE..., 2020).

Em contrapartida, o destino das exportações foi o elemento de maior contribuição para as receitas advindas do comércio externo de minérios de ferro não aglomerados e seus concentrados, posto que o valor desta componente saltou de $-0,14 \%$ para $9.132,98 \%$. Tais resultados podem ser explicados por um aumento, nos últimos anos, nas vendas externas de produtos siderúrgicos brasileiros. Para o Anuário Estatístico 2019 (INSTITUTO AÇO BRASIL, 2019), outro elemento apontado no crescimento das exportações de minérios de ferro é a demanda por aço, pois, conforme Carvalho (2017), há estreita relação entre produção de aço e consumo de minério ferroso, e o Anuário (2019) indica aumento do consumo de aço bruto entre os anos de 2013 a 2018 pelas principais potências desse segmento.

Com relação ao efeito competitividade, ocorreu uma redução entre os períodos I (2004/2008 a 2009/2013) e II (2009/2013 a 2014/2018), conforme mostra a Tabela 8. Bitten- 
court, Fontes e Campos (2012) esclarecem que o efeito competitividade mensura os ganhos/ perdas na participação nos mercados de cada país, que decorre de preços e/ou custos, melhorias tecnológicas, entres outros, ou seja, este efeito é endógeno, sendo definido por fatores internos às nações. Com relação à mineração de ferro brasileira, embora as grandes produtoras almejem a redução dos preços, conforme salientado, cabe destacar que ainda prevalecem alguns gargalos, uma vez que, para Miguel (2013), o transporte dos minérios de ferro pode ser realizado por meios marítimos, terrestre ou aéreo, mas, para o escoamento até os portos, o transporte interno se torna um grande desafio resultado de uma infraestrutura precária e deficiente, no caso do Brasil. Ademais, para o autor, tais dificuldades geram atrasos aos importadores, e algumas vezes os pedidos podem ser cancelados, acarretando mais prejuízo.

Apesar da trajetória decrescente da participação das exportações brasileiras de minérios de ferro no mercado internacional, Brasil (2017) destaca que a mineração do ferro é uma das atividades mais importantes do país, tendo em vista os recursos financeiros envolvidos, como a logística de transporte rodoviário, ferroviário e marítimo e que o setor de mineração brasileiro ocupa um lugar de protagonista no mercado mundial destas commodities.

\section{CONSIDERAÇÕES FINAIS}

Em termos de resultados, reitera-se que o IVCR mostrou que os Estados de Minas Gerais e Pará possuem vantagem comparativa revelada nas exportações de minérios de ferro não aglomerados, estando de acordo com a literatura que discute a temática. Em relação aos minérios de ferro aglomerados, o Estado do Espírito Santo apresentou valores expressivos para o IVCR. Esse resultado pode ser atribuído aos investimentos feitos na região, à medida que o Estado de Minas Gerais registrou desvantagem comparativa para esse segmento para a maioria dos anos analisados, com exceção de 2016, 2017 e 2018. Já o IVCRS e o RCAV permitiram inferir vantagem comparativa para os Estados de Minas Gerais e Pará com relação aos minérios de ferro não aglomerados, e para o Estado do Espírito Santo no que diz respeito aos minérios de ferro aglomerados. O mesmo não ocorreu com este segmento para Minas Gerais. Tais vantagens obtidas por estes segmentos destacados são justificadas pelo elevado aporte de investimentos das empresas exploradoras de minérios de ferro, materializados em pesquisas, inovação e logísticas, que proporcionam competitividade no comércio exterior.

No que se refere ao modelo Constant Market Share, empregado para verificar as fontes de crescimento das exportações brasileiras de minérios de ferro aglomerados e não aglomerados e seus concentrados, o efeito crescimento do comércio mundial apresentou sinal positivo no primeiro período e negativo no segundo, na medida em que o efeito destino das exportações foi o que mais contribuiu para o comércio externo brasileiro de ambos os segmentos dos minérios de ferro. Por outro lado, o efeito competitividade mostrou-se positivo e crescente entre os dois períodos analisados para os minérios de ferro não aglomerados; e decrescente, embora positivo, para os minérios de ferro não aglomerados, sinalizando que este último segmento vem perdendo participação no mercado mundial destas commodities, estando associada ao aumento de preços.

Em síntese, percebe-se, com base na literatura especializada que trata de minérios de ferro, que, em termos agregados, o mesmo possui vantagem comparativa nos períodos analisados. Essa inferência foi corroborada neste estudo. Quando, todavia, se trata da análise desagrega- 
da por segmentos, verifica-se que os minérios de ferro aglomerados não registraram vantagem comparativa para Minas Gerais em todos os anos contemplados, sinalizando que o processo de aglomeração do minério de ferro pode ser recente no Estado. Esta constatação ratifica a importância da análise desagregada desse setor, uma das contribuições deste estudo, pois permite a formulação de políticas e estratégias empresariais direcionadas para os segmentos que possuem vantagens em suas exportações, bem como se destacam na pauta exportadora dos Estados e do país.

Por fim, ressalta-se que o presente estudo procurou contribuir com a literatura econômica especializada mensurando o desempenho do exportador de minérios de ferro no Brasil por meio do IVCR, IVCRS e RCAV, além de determinar as fontes de crescimento das exportações destes produtos. Em discussões posteriores, no entanto, sugere-se analisar o componente das exportações de minérios de ferro brasileiras considerando outras variáveis, como a taxa de câmbio e outros métodos, como vetores autorregressivos.

\section{REFERÊNCIAS}

ANM. Agência Nacional de Mineração. Informe Mineral 2018. Brasília: ANM, 2018.

ALMEIDA, E.; LIMA, P. S.; SILVA, L. M.; MAYORGA, R. D.; LIMA, F. Competitividade das exportações mundiais de plantas vivas e produtos de floricultura. Análise Econômica, Porto Alegre, RS, v. 25, n. 47, p. 189212, 2007.

BALANÇO VALE MAIS. Social, ambiental e econômico. Minas Gerais: Vale, jan./jun. 2018.

BALASSA, B. Trade Liberazation and "Revealed" Comparative Advantage. Manchester School of Economic and Social Studies, Oxford, v. 33, p. 99-123, 1965.

BENDER, S.; LI, K-W. The changing trade and revealed comparative advantages of Asian and Latin American manufacture exports. New Haven: Yale University; Economic Growth Center, 2002. 26 p.

BITTENCOURT, G. M.; FONTES, R. M. O.; CAMPOS, A. C. Determinantes das exportações brasileiras de etanol. Revista de Política Agrícola, Brasília, v. 21, n. 4, p. 4-19, 2012.

BLACK, C.; AVILA, R. I. Uma investigação sobre as exportações brasileiras no período recente. Indicadores Econômicos FEE, Porto Alegre, v. 40, n. 4, p. 41-50, 2013.

BRASIL, A. F. V. A mineração no Brasil: um enfoque ao minério de ferro ao longo da primeira década de 2000. 2017. Monografia (Graduação em Ciências Econômicas) - Universidade Federal de Ouro Preto, Ufop, Mariana, 2017.

CARVALHO, F. M. A. Método “Constant Market Share” (CMS). In: SANTOS, M. L.; VIEIRA, W. C. Métodos quantitativos em economia. Viçosa: UFV, 2004. p. 225-241.

CARVALHO, V. V. Mercado internacional de minério de ferro. 2017. Monografia (Graduação em Engenharia de Minas) - Universidade Federal de Ouro Preto, Ufop, Ouro Preto, 2017.

CASSANO, F. A. A teoria econômica e o comércio internacional. Pesquisa \& Debate, São Paulo, n. 1 (21), v. 13, p. 112-128, 2002.

CORONEL, D. A.; MACHADO, J. A. D.; CARVALHO, F. M. A. Análise da competitividade das exportações do complexo soja brasileiro de 1995 a 2006: uma abordagem de market share. Revista de Economia Contemporânea, Rio de Janeiro, v. 13, n. 2, p. 281-307, 2009.

CORONEL, D. A.; SOUSA, E. P.; AMORIM, A. L. Desempenho exportador do mel natural nos Estados brasileiros. Pesquisa \& Debate, São Paulo, v. 22, n. 2 (40), p. 343-360, 2011.

COUTINHO, E. S.; LANA-PEIXOTO, F. V.; RIBEIRO FILHO, P. Z.; AMARAL, H. F. De Smith a Porter: um ensaio sobre as teorias de comércio exterior. Revista de Gestão USP, São Paulo, v. 12, n. 4, p. 101-113, out./dez. 2005.

COUTINHO, L. G.; FERRAZ, J. C. Estudo da competitividade da indústria brasileira: sistema de indicadores da competitividade. Campinas: IE/Unicamp - IEI/UFRJ - FDC - Funcex, 1993.

DAVANZO, J. N.; OLIVEIRA, F. F.; PORTUGUAL JÚNIOR, P. S.; SANTOS PORTUGUAL, N. O comércio internacional e a política protecionista brasileira: uma análise no período recente. In: SIMPÓSIO DE EXCELÊNCIA EM QUALIDADE DE NEGÓCIOS, 14., 2017. Anais... Resende, RJ: Seget, 2017. 
DNPM. Departamento Nacional de Produção Mineral. Informe Mineral 2009. Brasília: DNPM, 2009. DNPM. Departamento Nacional de Produção Mineral. Informe Mineral 2015. Brasília: DNPM, 2015. DNPM. Departamento Nacional de Produção Mineral. Informe Mineral do Estado do Pará 2016. Belém, PA: DNPM, jan. 2017.

DÓREA, R. J. S.; CONCEIÇÃO, R. L. C.; COSTA, J. F.; BRAGA, T. B.; REZENDE, A. A. Uma análise das exportações de minério de ferro do Estado de Minas Gerais sob a perspectiva da vantagem comparativa revelada e da taxa de cobertura, entre os anos de 1997 a 2014. In: SEMANA DE ECONOMIA DA UNIVERSIDADE ESTADUAL DO SUDOESTE DA BAHIA, 14., 2015. Anais [...]. Vitória da Conquista, BA: Editora Uesb, 2015.

ESPERANÇA, A. A.; LíRIO, V. S.; MENDONÇA, T. G. Análise comparativa do desempenho exportador de flores e plantas ornamentais nos Estados de São Paulo e Ceará. Revista Econômica do Nordeste, Fortaleza, CE, v. 42, n. 2, p. 259-286, 2011.

FERREIRA, G. E. A competitividade da mineração de ferro no Brasil. Rio de Janeiro: Cetem; MCT, 2001. (Série estudos e documentos).

FRANCK, A. G. S.; CORONEL, D. A.; SILVA, M. L.; SILVA, R. A. Competitividade das exportações australianas e brasileiras de minério de ferro para a China (1999-2014). Revista do Núcleo de Estudos de Economia Catarinense, Florianópolis, v. 4, n. 8, p. 28-43, 2015.

HINLOOPEN, J.; MARREWIJK, C. V. On the empirical distribution Balassa Index. Weltwirtschaftliches Archiv, v. 137, n. 1, p. 1-35, 2001.

INSTITUTO AÇO BRASIL. Anuário Estatístico 2019. Rio de Janeiro: Instituto Aço Brasil, 2019.

IBRAM. Instituto Brasileiro de Mineração. Informações sobre a economia mineral brasileira 2015. Brasília: Ibram, 2015.

INTERNATIONAL TRADE STATISTICS DATABASE. UN Comtrade Database. Disponível em: http://comtrade. un.org/. Acesso em: 16 jan. 2020.

LAURSEN, K. Revealed Comparative Advantage and the Alternatives as Measures of International Specialization. DRUID Working Paper, n. 98-30, Conpenhagem: Danish Research Unit for Industrial Dynamics, 1998. LEAMER, E.E., STERN, R.M. Quantitative international economics. Journal of International Economics 1, Aldine Publishing Company, p. 171-183, 1970.

LEDERMAN, D.; OLARREAGA, M.; RUBIANO, E. Specialization and adjustment during the growth of China and India: the Latin American experience. Policy Research Working Paper n. 4318. Washington, D.C.: The World Bank, 2007.

LIMA, M. G.; LÉLIS, M. T. C.; CUNHA, A. M. Comércio internacional e competitividade do Brasil: um estudo comparativo utilizando Constant-Market-Share para o período de 2000-2011. Economia e Sociedade, Campinas, v. 24, n. 2 (54), p. 419-448, 2015.

LOPES, M. A. B.; FILGUEIRAS, G. C.; ROCHA, V. C. A.; SANTOS, R. B. N. Estudo da competitividade da carne de frango brasileira no mercado internacional: 1990-2002. In: CONGRESSO DA SOCIEDADE BRASILEIRA DE ECONOMIA, ADMINISTRAÇÃO E SOCIOLOGIA RURAL, 2005. Anais [...]. Ribeirão Preto, SP: Sober, 2005. LOPES, M. M.; SILVA, R. A.; CORONEL, D. A. Competitividade das exportações brasileiras de minério de ferro (1999-2012). In: FÓRUM INTERNACIONAL ECOINOVAR, 2., 2013. Santa Maria. Anais [...]. Santa Maria, RS, 2013.

LOPES, M. M.; SILVA, R. A.; FRIES, C. D.; CORONEL, D. A. Análise das exportações brasileiras de soja em grão e de minério de ferro para a China (1999-2012). Revista de Administração, Contabilidade e Economia da Fundace, Ribeirão Preto, SP, v. 5, n. 1, p. 1-11, maio 2014.

MARTINS, A. P.; SILVIA, F. A.; GOMES, M. F. M.; ROSADO, P. L. Desempenho do comércio exterior em Minas Gerais: estrutura, vantagem comparativa e comércio intraidústria. Revista Economia e Agronegócio, Viçosa, MG, v. 8, n. 2, p. 221-250, 2010.

MDIC. Ministério da Indústria, Comércio Exterior e Serviços. Comex Stat. Disponível em: http://comexstat.mdic.gov.br/pt/home. Acesso em: 5 mar. 2019.

MIGUEL, A. P. A infraestrutura brasileira e os desafios logísticos para o escoamento do minério de ferro para exportação. 2013. Monografia (Especialização em Gestão Estratégica) - Universidade Federal de Minas Gerais, UFMG, Belo Horizonte, 2013.

MOREIRA, U. Teorias do comércio internacional: um debate sobre a relação entre crescimento econômico e inserção externa. Revista de Economia Política, São Paulo, n. 2(127), v. 32, p. 213-228, abr./jun. 2012.

OLIVEIRA, I. T. M. Livre comércio versus protecionismo: uma análise das principais teorias do comércio internacional. Revista Urutágua - Revista Acadêmica Multidisciplinar, Maringá, PR, n. 11, 18 p., 2007. 
PAIS, P. S. M.; GOMES, M. F. M.; CORONEL, D. A. A análise da competitividade das exportações brasileiras de minério de ferro, de 2000 a 2008. Revista de Administração Mackenzie, São Paulo, v. 13, n. 4, p. 121145, 2012.

PEREIRA, F. A. C.; FERNANDES, E. F. R.; PENA, H. W. A. Análise do desempenho das exportações brasileiras no setor de minérios de ferro e seus concentrados na dinâmica do comércio exterior por meio da matriz competitividade, 2015-2016. Revista Observatorio de la Economía Latinoamericana, Brasil, sept. 2017. Disponível em: http://www.eumed.net/cursecon/ecolat/br/2017/exportacoes-brasileiras.html. Acesso em: 22 jan. 2020.

PINHEIRO, W. F.; FERREIRA FILHO, O. B.; NEVES, C. A. R. (coord. geral). Anuário Mineral Brasileiro: principais substâncias metálicas. Brasília: DNPM, 2016.

PORTER, M. E. A vantagem competitiva das nações. Rio de Janeiro: Campus, 1993.

RELATÓRIO FORM 20-F. Relatório anual do exercício de 2017, 2018. Vale S.A. 2019. Disponível em: http:// www.vale.com/PT/investors/information-market/annual-reports/20f/20FDocs/Vale_20F_2017_p.pdf. Acesso em: 24 mar. 2019.

RICARDO, D. Princípios de economia política e tributação. São Paulo: Nova Cultura, 1996.

RODRIGUES, J. S.; ARÊDES, A. F. Competitividade e desempenho das exportações brasileira do melão. Perspectivas on-line, Campos dos Goytacazes, v. 18, n. 7, p. 17-25, 2017.

SANTOS, J. L. S.; SOUSA, E. P. Competitividade das exportações brasileiras de melão. Revista de Política Agrícola, Brasília, v. 26, n. 3, p. 31-43, 2017.

SANTOS, J. L. S.; SOUSA, E. P. Competitividade das exportações brasileiras de banana. Estudo \& Debate, Lajeado, v. 26, n. 2, p. 52-73, 2019.

SILVA, A. D. B.; HIDALGO, A. B. A concorrência entre o Brasil e China no mercado sul-africano: uma aplicação do modelo Constant-Market-Share. Revista Economia Contemporânea, Rio de Janeiro, v. 16, n. 1, p. 88-106, jan./abr. 2012.

SILVA, M. L.; SILVA, R. A.; CORONEL, D. A. Padrão de especialização do comércio internacional do Paraná (1999-2012). Desenvolvimento em Questão, v. 15, n. 40, p. 258-287, jul./set. 2017.

TRIPOLI, A. C. K.; PRATES, R. C. Certificação ambiental e internacionalização: uma análise do setor madeireiro brasileiro. Desenvolvimento em Questão, v. 13, n. 31, p. 322-355, jul./set. 2015. 